\title{
Diabetes-Related Distress Among People with Type 2 Diabetes in Ho Chi Minh City, Vietnam: Prevalence and Associated Factors
}

This article was published in the following Dove Press journal:

Diabetes, Metabolic Syndrome and Obesity: Targets and Therapy

\section{Giao Huynh (D) \\ Thien Thuan Tran (1D) \\ Thi Hoai Thuong Do $\mathbb{D D}^{\prime}$ \\ Thi Thuy Dung Truong' \\ Phuc Thinh Ong ${ }^{2}$ \\ Thi Ngoc Han Nguyen (1D) ${ }^{3}$ \\ Le An Pham ${ }^{4}$}

'Faculty of Public Health, University of Medicine and Pharmacy at Ho Chi Minh City, Ho Chi Minh City, Vietnam; ${ }^{2}$ Center for Population Health Sciences, Hanoi University of Public Health, Hanoi, Vietnam; ${ }^{3}$ Infection Control Department, University Medical Center Ho Chi Minh City, Ho Chi Minh City, Vietnam; ${ }^{4}$ Family Medicine Training Center, University of Medicine and Pharmacy at Ho Chi Minh City, Ho Chi Minh City, Vietnam
Correspondence: Le An Pham; Giao Huynh

University of Medicine and Pharmacy at

Ho Chi Minh City, 217 Hong Bang Street,

District 5, Ho Chi Minh City, Vietnam

Tel +84908I53743; +84908608338

Email phamlean@uq.edu.au;

hgiaoytcc@ump.edu.vn
Background: Diabetes-related distress (DRD) refers to the condition of negative emotion as a result of living with diabetes and the burden of self-care. This study aims to evaluate the prevalence and associated factors of DRD among people with type 2 diabetes.

Methods: A cross-sectional study was carried out on people with Type 2 Diabetes at three hospitals in Ho Chi Minh City, between April and November 2020. The study used the Vietnamese version of the Diabetes Distress Scale (DDS) which includes 17 items. The mean total distress score was calculated on the average of the 17 items. A mean score of equal to 2.0 or higher was classified as moderate to severe distress. Descriptive statistics were performed by frequency and percentage, and the multivariate Logistic Regression Analysis was used to assess information where $\mathrm{p}$-value $<0.05$ was considered statistically significant. Results: A total of 517 participants, who were mainly over 60 years old $(56.8 \%)$ with females being $65.0 \%$, participated in the study. Results showed that $23.6 \%$ and $5.8 \%$ of them, respectively, were found as being moderately or highly distressed. Some factors that correlated with the total distress results included age, timescale of diabetes, and glycemic control level (HbA1c). The rate of total distress in those who were over 60 years old and had a $\mathrm{HbA1} \mathrm{c}<7$ were less prevalent than those who were under 60 , and had a $\mathrm{HbA1c} \geq 7$ (OR 0.5 95\% CI 0.3-0.7; OR 0.5 95\% CI: 0.3-0.9, respectively, all $\mathrm{p}<0.05$ ), whilst the timescale of diabetes between 5 and 10 years was significantly more prevalent than those who had a timescale less 5 years (OR $1.895 \%$ CI 1.1-2.9, p<0.05).

Conclusion: A high rate of distress exists in people with diabetes. Therefore, combining the evaluation of distress as part of the regular diagnostic procedures of diabetes care, and recommending physicians apply a comprehensive approach to diabetes management, is necessary.

Keywords: diabetes, diabetes distress scale, distress, Vietnam

\section{Introduction}

Diabetes, which is one of the most common chronic non-communicable diseases globally, is recorded as the seventh leading cause of death worldwide. ${ }^{1}$ As of 2016 , the World Health Organization (WHO) estimated 1.6 million deaths were directly caused by diabetes. Moreover, the prevalence of diabetes has grown rapidly in low to middle-income countries rather than in higher-income countries. ${ }^{1,2}$ Globally, there are over 463 million diabetes sufferers and it is predicted this figure will rise to 700 million by 2045 , of which about $90 \%$ were type 2 diabetes (T2D). ${ }^{3}$ Of note, diabetes is a considerable problem in Vietnam, in which its prevalence has 
doubled over the past 10 years, from $2.6 \%$ to $5.7 \%$ between 2010 and $2020 .^{3}$ Diabetes mellitus is a metabolic disease caused by prolonged high blood sugar levels, which leads to complications, including microvascular (retinopathy, nephropathy) and macrovascular (heart attacks, strokes, and insufficiency in blood flow to legs). ${ }^{4}$ Living with diabetes long term, sufferers can be impacted on not only individual's physical health but also negative psychosocial problems due to the threat of complications and the social burden of the condition which can result in an emotional burden known as "diabetes distress". Diabetes-related distress consists of multidimensional aspects including worry, conflict, frustration that is affected by the type of diabetes, treatment regimen. ${ }^{6}$ The Problem Areas in Diabetes scale (PAID) has been developed to assess diabetes distress ${ }^{7}$ but it has some limitations and a more recent development the Diabetes Distress Scale (DDS), has been developed as a new instrument that will evaluate diabetes-related distress in research and clinical practices, plus it was approved for use in clinical practices by the Canadian Diabetes Association in $2016 .{ }^{8}$ It has been translated into multiple languages and for use across a number of countries including Malaysia, Thailand, Brazil and Turkey. ${ }^{9-12}$ In the DDS English version, it has been divided into four domains, including distress related with emotional burden (patients were angry or scared when living with diabetes); diabetes-related interpersonal distress (patients thought that their friends or family members did not understand their difficulties when living with diabetes); physicianrelated distress (patients thought that the physicians did not thoroughly consult on how to control their condition); and Regimen-related distress (Patients were concerned about not enough testing of their glycemia on a regular basis). ${ }^{8}$ With the burden of the incidence of diabetes increasing, exploring ways to enhance self-care is essential, especially the understanding of the emotional aspects in diabetes, plays an important role in treatment where patients are centered and collaborated. Additionally, the presence of DRD depends on the characteristics of the population and other psychosocial factors. ${ }^{13}$ However, there is still little data and the psychosocial dimensions of diabetes patients, which has not been largely considered in Vietnam. Therefore, this study aims to determine the prevalence and factors associated with distress among T2D patients in Ho Chi Minh City, Vietnam, using of the Vietnamese version of the DDS17, which was translated and adapted into the Vietnamese version from the original
English instrument, ${ }^{14}$ in order to deliver more effective interventions, to enhance the quality of management and treatment for individuals that are struggling to cope with diabetes.

\section{Methods \\ Study Population}

A cross-sectional study was collected between April and November 2020 at the outpatient departments of three district hospitals of Ho Chi Minh City. A convenience sampling strategy was performed on all adult patients who were diagnosed with Type 2 Diabetes for at least 3 months, however, patients who had gestational diabetes, cancer, cognitive limitations, or missed out on any items in DDS were excluded. All patients were informed of the objectives of the study and signed the consent form before participating.

\section{Data Collection}

Data was collected using a structured questionnaire from the Diabetes Distress Scale (DDS). Participants were interviewed face to face, responding to each of the 17 items of DDS and responded using a six-point Likert scale (from "not a problem" to "a very serious problem") relating to distress experienced during the last month. The Vietnamese version of DDS-17 items was translated and adapted to Vietnamese showing good internal consistency with Cronbach's alpha of 0.94 and high validity. ${ }^{14}$ The interview also included the gathering of baseline demographics of the participants such as age, gender, marital status, education, gross household income, occupation, history of illness, timescale of diabetes, medication and complications, while the HbAlc level was recorded via medical records. It took approximately $10-15$ minutes to complete one interview.

\section{Method of Analysis}

A 6-point Likert scale ranging between 1 (not a problem) and 6 (a very serious problem) was used to assess the score of each item. The questionnaire assessed four subscales of DRD, including five items for emotional burden, four items regarding physician-related distress, five items towards regimen-related distress, and three items for interpersonal-related distress. Each subscale was scored separately by dividing the sum of its item scores by the number of the items. Also, a mean of total distress score was counted by a calculating the sum of the 17 items and 
dividing by 17 . A mean score of less than 2.0 was considered little or no distress, and equal to 2.0 , or higher, reported a level of distress (2.0 to less than 3.0 indicated moderate distress, and a score of 3.0 or more was high distress). ${ }^{14}$

Stata version 13.0 software was used to analyze data. Descriptive statistics were performed with frequency and percentage for categorical variables. Chi-square test or Fisher's exact test was used to analyze the relationship between the dependent (subscale and total diabetes distress) and independent variables (characteristic of participants). All factors which had a significance level p-value $<0.05$ in the bivariate analysis were included in the multivariate analysis by the Logistic regression model. All of the significant differences of variables were considered if the p-value showed $<0.05$.

\section{Ethical Approval}

Our research complied with the Declaration of Helsinki. All eligible participants were informed of the aims of the study and agreed, completing a consent form, before participating. Our study proposal was approved by the Ethics Council of University of Medicine and Pharmacy at Ho Chi Minh City (protocol number 720/UMP - BOARD).

\section{Results}

\section{Baseline Characteristics of Participants}

As shown in Table 1, a total of 517 people with DM participate and were predominately female $(65.0 \%)$, over 60 years old $(56.8 \%)$, the timescale for DM equal to 5 years or more $(57.4 \%)$, married $(60.7 \%)$, and high school level education (38.7\%). Most participants had a history of hypertension (66.2\%), taking medication (72.2\%), and only about one-third of patients reported being $\mathrm{HbAlc}$ $<7 \%$. A minority of them had reported complications $(16.6 \%)$.

\section{Factors Associated with Distress Among Type 2 Diabetes Patients}

As depicted in Table 2, the total of DDS was 29.4\% which consisted of $23.6 \%$ moderate and $5.8 \%$ of high DRD. Besides, a high percentage of distress was found in emotional and regimen-related distress with $45.3 \%$ and $30.6 \%$, respectively. In the bivariate analyses, we found a statistically significant association between the total Diabetes-related distress and factors including the age of participants, timescale, medication, and $\mathrm{HbAlc}$ level $(\mathrm{p}<0.05)$ (Table 3$)$. Table 4 summarizes the results of the multiple logistic regression model of factors associated with Diabetes-related distress. In relation to emotional burden, participants who were equal to 60 years of age or older, with an education level not more than primary school and taking oral hypoglycemic drugs, were significantly less likely to be distressed, which is opposite to those who were under 60 years of age, having completed high school level education or above and were being prescribed insulin or combination treatment (OR 0.7, 95\% CI: 0.4-0.9; OR 0.5, 95\% CI: 0.3-0.8, OR 0.6, 95\% CI: $0.4-0.9$, respectively, all $\mathrm{p}<0.05$ ). For physicianrelated distress, the findings showed that single patients, who had only a primary school education, were less likely to be distressed, compared with those who were married and educated to high school or higher (OR $0.695 \% \mathrm{CI}$ 0.3-0.9, OR 0.4, 95\% CI 0.2-0.8, respectively, all p<0.05). We found that patients who were currently retired or a housewife, were less likely to have interpersonal related distress over those patients who were classified as a worker (OR 0.4, 95\% CI: 0.2-0.8, p<0.05). Besides, patients who were sellers (shop owners) or retired/housewives and equal to 60 years or older, were less likely to have regimen-related distress compared to those who were workers and under 60 years old $(\mathrm{p}<0.05)$. In relation to total distress, the rate of total distress in those who were over 60 years of age was less than those who were under 60 years of age (OR $0.595 \%$ CI $0.3-0.7, \mathrm{p}<0.05$ ). Conversely, those with a timescale 5-10 years were significantly higher than those who had a timescale of under 5 years (OR $1.895 \%$ CI 1.1-2.9, p<0.05). In addition, all distress subscales were associated with glycemic control level (HbAlc), except physician-related distress, whereby the lower emotional burden, regimen-related distress, interpersonal distress, and the total distress had a significant correlation with good glycemic control (HbA1C levels of <7) (OR 0.6 95\% CI: 0.4-0.9, OR 0.4 95\% CI: $0.2-0.6$, OR 0.4 95\% CI: $0.2-0.9$, OR $0.595 \%$ CI: $0.3-0.9$, respectively, all $\mathrm{p}<0.05$ ).

\section{Discussion}

This is the first study to highlight the prevalence and factors associated with diabetes distress in Vietnam in relation to the background of diabetes, which is increasing at alarming rates, as well as exploring the risk factors for diabetes distress. We found that around $23.6 \%$ of the participants had moderate DRD while $5.8 \%$ of them had high DRD. These results are lower than those in previous studies in many countries such as 
Table I Characteristics of the Participants $(n=517)$

\begin{tabular}{|c|c|}
\hline Baseline Characteristics & n (\%) \\
\hline \multicolumn{2}{|l|}{ Age } \\
\hline$<60$ & $223(43.2)$ \\
\hline$\geq 60$ & $294(56.8)$ \\
\hline \multicolumn{2}{|l|}{ Gender } \\
\hline Male & $|8|(35.0)$ \\
\hline Female & $336(65.0)$ \\
\hline \multicolumn{2}{|l|}{ Timescale (years) } \\
\hline$<5$ & $220(42.6)$ \\
\hline $5-10$ & $|5|(29.2)$ \\
\hline$>10$ & $146(28.2)$ \\
\hline \multicolumn{2}{|l|}{ Marital status } \\
\hline Married & $314(60.7)$ \\
\hline Single & $203(39.3)$ \\
\hline \multicolumn{2}{|l|}{ Education } \\
\hline Primary school & $180(34.8)$ \\
\hline Secondary school & $137(26.5)$ \\
\hline High school and higher & $200(38.7)$ \\
\hline \multicolumn{2}{|l|}{ Gross household income } \\
\hline High & $13(2.5)$ \\
\hline Medium & $446(86.3)$ \\
\hline Low & $58(I \mid .2)$ \\
\hline \multicolumn{2}{|l|}{ Occupation } \\
\hline Retired/Housewife & $372(72.0)$ \\
\hline Worker & $87(16.8)$ \\
\hline Seller & $58(11.2)$ \\
\hline History of illness (Yes) & $44 I(85.3)$ \\
\hline Hypertension & $292(66.2)$ \\
\hline Dyslipidemia/Hypercholesterolemia & $190(46.2)$ \\
\hline Ischemic heart disease & $|2|(37.9)$ \\
\hline Musculoskeletal disorders & $93(26.7)$ \\
\hline \multicolumn{2}{|l|}{ Medication } \\
\hline Oral hypoglycemic drugs & $373(72.2)$ \\
\hline Insulin or combination & I 44(27.8) \\
\hline \multicolumn{2}{|l|}{ HbAlc } \\
\hline$<7 \%$ & $163(31.5)$ \\
\hline$\geq 7 \%$ & $354(68.5)$ \\
\hline Complications (Yes) & $86(16.6)$ \\
\hline Retinopathy & $29(5.6)$ \\
\hline Peripheral vascular disease & $22(4.3)$ \\
\hline Neuropathy & $2 I(4.1)$ \\
\hline Nephropathy & $14(2.6)$ \\
\hline
\end{tabular}

Saudi Arabia, Bangladesh, China, Canada, the USA and Malaysia $(25.0 \%, 48.5 \%, 43.0 \%, 39.0 \%, 51.3 \%, 49.2 \%$, respectively). ${ }^{15-20}$ These results indicated that diabetes distress
Table 2 Level of Diabetes Distress Scale-I7 Items (DDS-17) $(n=5 \mid 7)$

\begin{tabular}{|l|c|c|}
\hline \multirow{2}{*}{ Subscales } & \multicolumn{2}{|c|}{$\begin{array}{c}\text { Level of Diabetes-Related } \\
\text { Distress }\end{array}$} \\
\cline { 2 - 3 } & Yes & No \\
\hline Total distress & $152(29.4)$ & $365(70.6)$ \\
Moderate & $122(23.6)$ & \\
High & $30(5.8)$ & \\
\hline Emotional distress & $234(45.3)$ & $283(54.7)$ \\
Moderate & $81(15.7)$ & \\
High & $153(29.6)$ & \\
\hline Regimen-related distress & $168(30.6)$ & $359(69.4)$ \\
Moderate & $101(19.5)$ & \\
High & $57(11.1)$ & \\
\hline Physician-related distress & $67(13.0)$ & \multirow{2}{*}{$450(87.0)$} \\
Moderate & $28(5.4)$ & \\
High & $39(7.6)$ & \\
\hline Interpersonal distress & $41(7.9)$ & \multirow{2}{*}{$476(92.1)$} \\
Moderate & $11(2.1)$ & \\
High & $30(5.8)$ & \\
\hline
\end{tabular}

varies widely in different countries and healthcare settings and it is not similar in terms of demographics, clinical characteristics in each geographical region and cultural backgrounds. Some previous studies which showed that advancing age was positively associated with the rising prevalence of diabetes and women were more likely to have diabetes than men. ${ }^{21}$ Another important finding was that the highest level in the subscales of DDS was emotional and regimen-related distress. This finding was also reported by Aljuaid et al. ${ }^{15}$ As mentioned in the literature review, the emotional and regimen distress, where there were some negative emotions such as desperation and dissension, is defined as being an unpleasant emotion from thinking about the prospect of a future living with diabetes and maintaining self-care of their condition. ${ }^{9}$ Another important finding was that the younger aged participants reported a higher DRD in all three domains (emotional, regimenrelated, total of distress). This finding was also reported by Wardian J. in $2014 .^{22}$ It is possible that younger people have to be responsible for their family, work and financial challenges, while managing the cost and time of diabetes which can be high and long-lasting in Vietnam. These factors may be contributing to the results of their high distress levels. Therefore, the management of diabetes patients should be considered and take in the consultation of emotional burden problems by 
Table 3 Associated Factors Between Total of Diabetes Distress and Characteristic of Participants $(n=5 \mid 7)$

\begin{tabular}{|c|c|c|c|}
\hline \multirow[t]{2}{*}{ Variable } & \multicolumn{2}{|c|}{ Total Distress } & \multirow[t]{2}{*}{$\mathbf{p}$} \\
\hline & $\begin{array}{c}\text { Yes }(n= \\
152)\end{array}$ & $\begin{array}{c}\text { No } \\
(n=365)\end{array}$ & \\
\hline \multicolumn{4}{|l|}{ Age } \\
\hline$<60$ & $8 \mathrm{I}(53.3)$ & $142(38.9)$ & $0.003^{*}$ \\
\hline$\geq 60$ & 7I(46.7) & $223(61.1)$ & \\
\hline \multicolumn{4}{|l|}{ Gender } \\
\hline Male & $54(35.5)$ & $127(34.8)$ & 0.874 \\
\hline Female & $98(64.5)$ & $238(65.2)$ & \\
\hline \multicolumn{4}{|l|}{ Timescale (Years) } \\
\hline$<5$ & $53(34.9)$ & I67(45.8) & \\
\hline $5-10$ & $54(35.5)$ & $97(26.6)$ & $0.048 *$ \\
\hline$>10$ & $45(29.6)$ & $101(27.6)$ & \\
\hline \multicolumn{4}{|l|}{ Marital status } \\
\hline Married & $94(61.9)$ & $220(60.3)$ & 0.739 \\
\hline Single & $58(38.2)$ & $145(39.7)$ & \\
\hline \multicolumn{4}{|l|}{ Education } \\
\hline Primary school & $50(32.9)$ & $130(35.6)$ & \\
\hline Secondary school & $4 I(26.9)$ & $96(26.3)$ & 0.834 \\
\hline High school and higher & $6 I(40.2)$ & $139(38.1)$ & \\
\hline \multicolumn{4}{|l|}{$\begin{array}{l}\text { Gross household } \\
\text { income }\end{array}$} \\
\hline High & $6(3.9)$ & $7(1.9)$ & \\
\hline Medium & $123(80.9)$ & $323(88.5)$ & 0.067 \\
\hline Low & $23(15.2)$ & $35(88.6)$ & \\
\hline \multicolumn{4}{|l|}{ Occupation } \\
\hline Worker & $31(20.4)$ & $56(\mid 5.3)$ & \\
\hline Retired/Housewife & $105(69.1)$ & $267(73.2)$ & 0.374 \\
\hline Seller & $16(10.5)$ & $42(11.5)$ & \\
\hline \multicolumn{4}{|l|}{ History of illness } \\
\hline Yes & 135(88.8) & $306(83.8)$ & 0.145 \\
\hline No & $17(\mid 1.2)$ & $59(16.2)$ & \\
\hline \multicolumn{4}{|l|}{ Medication } \\
\hline Oral hypoglycemic drugs & $98(64.5)$ & $275(75.3)$ & $0.012 *$ \\
\hline Insulin or combination & $54(35.5)$ & $90(24.7)$ & \\
\hline \multicolumn{4}{|l|}{ HbAlc } \\
\hline$<7 \%$ & $34(22.4)$ & $129(35.3)$ & $0.004 *$ \\
\hline$\geq 7 \%$ & $118(77.6)$ & $236(64.7)$ & \\
\hline \multicolumn{4}{|l|}{ Complications } \\
\hline Yes & $32(21.1)$ & $54(14.8)$ & 0.092 \\
\hline No & $120(78.9)$ & $3 I I(85.2)$ & \\
\hline
\end{tabular}

Notes: Chi-squared or Fisher's exact test used for comparison between total distress and characteristic of participants; ${ }^{*} p<0.05$. physicians, during follow-up and the treatment process, as well as payment of health insurance to support them. One unanticipated finding was that participants who had an education level of completion of high school or above, reported higher levels of distress in the domain of physician and emotional distress. This outcome is contrary to that of Aljuaid et $\mathrm{al}^{15}$ and Islam et $\mathrm{al}^{17}$ who found that a lower education level was associated with more distress. This might suggest that patients who have a higher education, may need to discuss the aspects of the treatment process in more detail. Research was conducted in Ho Chi Minh City which is one of the largest and most crowded cities in Vietnam, the number of patients in outpatient departments are large and policies state that each physician is required to see 65 patients per day. ${ }^{23}$ Therefore, the patients have less time to discuss details with their physician, which leads to a higher level of distress in the domains of emotion and physician. In our study, the timescale of diabetes over 5 years reported higher distress in relation to total distress. However, the finding in Islam M.'s study showed that distress only related to emotional, physician-related, and regimen distress $^{17}$ as well as Aljuaid et al found that duration of diabetes was not associated with distress, ${ }^{15}$ which can be possibly explained why patients in our study with long timings ( $>5$ years) have been faced with the high cost of treatment which may have affected their earning capabilities, so they are more likely to be distressed. Furthermore, our study showed that good glycemic control $(\mathrm{HbA} 1 \mathrm{c}<7)$ correlated with lower emotional distress, regimen-related distress, interpersonal distress, and total distress. This finding is consistent with Fisher et al who confirmed that diabetes distress was a bidirectional relationship with poorer glycemic control in patients with Type 2 Diabetes. ${ }^{24}$ Also, some previous studies have reported that $\mathrm{HbA1c}$ was associated with distress, especially high HbAlc levels, which can be related to emotional burden. ${ }^{25-29}$ Distress influences self-management and the type and quantity of medication taken by patients. Additionally, diabetes patients with negative psychological changes could experience negative impacts in metabolic control. Therefore, understanding the psychological problems and the changes in glycemic control levels should be considered.

Some limitations of this study included the fact that there is limitation of a cross-sectional study in extracting the cause-effect relationship between demographic characteristics of patients and distress was considered. 
Table 4 Results of Multiple Logistic Regression on Factors Associated with Components and Total Distress Diabetes ( $=517$ )

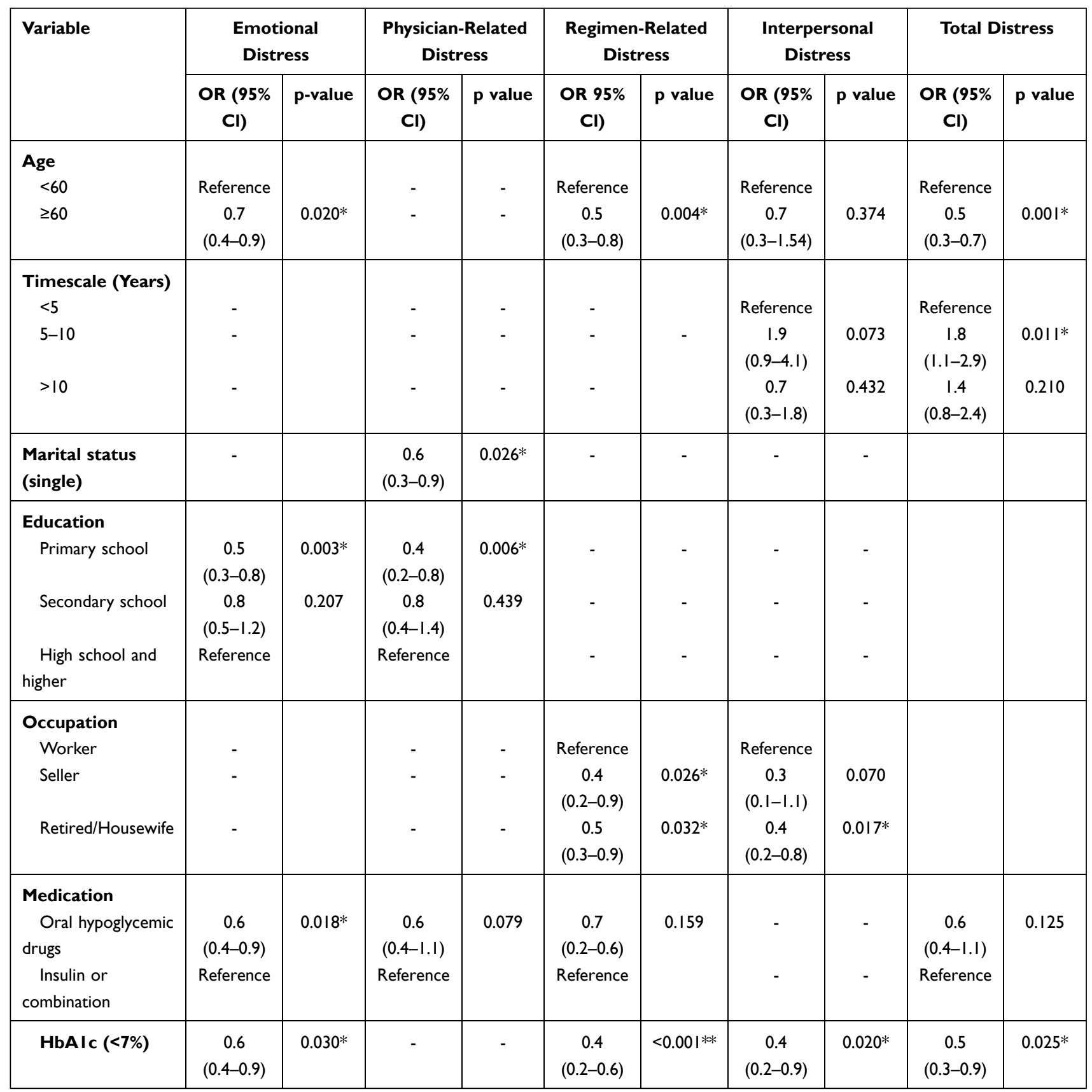

Notes: “-” if multiple Logistic regression is not available, ${ }^{*} p<0.05,{ }^{* *} p<0.001$.

\section{Conclusion}

A high rate of distress exists in people with diabetes. Therefore, combining the evaluation for distress as part of regular procedures into diabetes care, and recommending physicians apply a comprehensive approach for diabetes management, is necessary.

\section{Data Sharing Statement}

The data used to support this study are available from the first author upon request.

\section{Acknowledgments}

The authors would like to thank the nurse of the Endocrinology Departments as well as the patients for the time and effort they devoted to this study.

\section{Author Contributions}

All authors made substantial contributions to conception and design, acquisition of data, analysis, and interpretation of data, took part in revising the article critically for important intellectual content, gave final approval of the 
version to be published, and agree to be accountable for all aspects of the work.

\section{Funding}

This research received a grant from the University of Medicine and Pharmacy at Ho Chi Minh City.

\section{Disclosure}

The authors declare they have no conflicts of interest for this work.

\section{References}

1. WHO. The top 10 causes of death. 2018 Available from: https://www. who.int/news-room/fact-sheets/detail/the-top-10-causes-of-death. Assessed November 11, 2020.

2. WHO. Diabetes. 2020. Available from: https://www.who.int/newsroom/fact-sheets/detail/diabetes. Assessed November 11, 2020.

3. IDF Western Pacific. International diabetes federation. 2020. Available from: https://www.idf.org/our-network/regions-members /western-pacific/members/119-vietnam.html. Assessed November 11,2020

4. WHO. Diabetes programme. 2020. Available from: https://www.who. int/diabetes/action_online/basics/en/index3.html. Assessed November 11,2020 .

5. Rane K, Wajngot A, Wandell PE, Gåfvels C. Psychosocial problems in patients with newly diagnosed diabetes: number and characteristics. Diabetes Res Clin Pract. 2011;93(3):371-378. doi:10.1016/j.diabres.2011.05.009

6. Fisher L, Skaff MM, Mullan JT, et al. Clinical depression versus distress among patients with type 2 diabetes - not just a question of semantics. Diabetes Care. 2007;30:542-548. doi:10.2337/dc06-1614

7. Polonsky WH, Anderson BJ, Lohrer PA, et al. Assessment of diabetes-related distress. Diabetes Care. 1995;18(6):754-760. doi:10.2337/diacare.18.6.754

8. Polonsky WH, Fisher L, Earles J, et al. Assessing psychosocial distress in diabetes: development of the diabetes distress scale. Diabetes Care. 2005;28(3):626-631. doi:10.2337/diacare.28.3.626

9. Thanakwang K, Thinganjana W, Konggumnerd R. Psychometric properties of the Thai version of the diabetes distress scale in diabetic seniors. Clin Interv Aging. 2014;9:1353-1361. doi:10.2147/CIA. S67200

10. Telci Caklili O, Feyizoglu G, Tulu Colak S, Dizman N, Bozkurt Cakir SI, Oguz A. Reliability and validity of the Turkish version of the diabetes distress scale for type 2 diabetes and distress levels of the participants. Turk J Med Sci. 2020;50(2):464-470. doi:10.3906/sag1903-121

11. Chew BH, Mukhtar F, Sherina MS, Paimin F, Hassan NH, Jamaludin NK. The reliability and validity of the Malay version 17-item diabetes distress scale. Malays Fam Physician. 2015;10 (2):22-35.

12. Apolinario PP, Trevisan DD, Rodrigues RC, et al. Psychometric performance of the Brazilian version of the diabetes distress scale in patients with diabetes mellitus type 2. J Nurs Meas. 2016;24 (2):101-113. doi:10.1891/1061-3749.24.2.E101

13. Berry E, Lockhart S, Davies M, Lindsay JR, Dempster M. Diabetes distress: understanding the hidden struggles of living with diabetes and exploring intervention strategies. Postgrad Med J. 2015;91 (1075):278-283. doi:10.1136/postgradmedj-2014-133017

14. Thinh OP, Huynh A, Do TT, To GK. Translation and cross-cultural adaptation of the Vietnamese version of the diabetes distress scale. MedPharmRes. 2018;2:5-11. doi:10.32895/UMP.MPR.2.3.5
15. Aljuaid MO, Almutairi AM, Assiri MA, Almalki DM, Alswat K. Diabetes-related distress assessment among type 2 diabetes patients. J Diabetes Res. 2018;2018:7328128. doi:10.1155/2018/7328128

16. Fisher L, Glasgow RE, Strycker LA. The relationship between diabetes distress and clinical depression with glycemic control among patients with type 2 diabetes. Diabetes Care. 2010;33(5):1034-1036. doi: $10.2337 / \mathrm{dc} 09-2175$

17. Islam M, Karim M, Habib S, Yesmin K. Diabetes distress among type 2 diabetic patients. Int J Med Biomed Res. 2013;2(2):113-124. doi:10.14194/ijmbr.224

18. Zhou H, Zhu J, Liu L, et al. Diabetes-related distress and its associated factors among patients with type 2 diabetes mellitus in China. Psychiatry Res. 2017;252:45-50. doi:10.1016/j.psychres.2017.02.049

19. Wong EM, Afshar R, Qian H, Zhang M, Elliott TG, Tang TS. Diabetes distress, depression and glycemic control in a Canadian-based specialty care setting. Can J Diabetes. 2017;41 (4):362-365. doi:10.1016/j.jcjd.2016.11.006

20. Chew B-H, Vos R, Mohd-Sidik S, Rutten GEHM, Hashimoto K. Diabetes-related distress, depression and distress-depression among adults with type 2 diabetes mellitus in Malaysia. PLoS One. 2016;11 (3):e0152095. doi:10.1371/journal.pone.0152095

21. Nguyen CT, Pham NM, Lee AH, Binns CW. Prevalence of and risk factors for type 2 diabetes mellitus in Vietnam: a systematic review. Asia Pac J Public Health. 2015;27(6):588-600. doi:10.1177/ 1010539515595860

22. Wardian J, Sun F. Factors associated with diabetes-related distress: implications for diabetes self-management. Soc Work Health Care. 2014;53(4):364-381. doi:10.1080/00981389.2014.884038

23. Ministry of Health Vietnam. Circular 15: quy định thống nhất giá dịch vụ khám bệnh, chữa bệnh bảo hiểm y tế giữa các bệnh viện cùng hạng trên toàn quốc và hướng dẫn áp dụng giá, thanh toán chi phí khám bệnh, chữa bệnh trong một số trường hợp. 2018. Available from: https://thuvienphapluat.vn/van-ban/bao-hiem/Thong-tu-152018-TT-BYT-thong-nhat-gia-kham-chua-benh-bao-hiem-y-te-benhvien-cung-hang-384077.aspx. Assessed November 11, 2020.

24. Fisher L, Mullan JT, Arean P, et al. Diabetes distress but not clinical depression or depressive symptoms is associated with glycemic control in both cross-sectional and longitudinal analyses. Diabetes Care. 2010;33(1):23-28. doi:10.2337/dc09-1238

25. Tsujii S, Hayashino Y, Ishii H, Diabetes Distress and Care Registry at Tenri Study Group. Diabetes distress, but not depressive symptoms, is associated with glycaemic control among Japanese patients with type 2 diabetes: diabetes distress and care registry at Tenri (DDCRT 1). Diabet Med. 2012;29(11):1451-1455. doi:10.1111/j.14645491.2012.03647.x

26. Fisher L, Skaff MM, Mullan JT, Arean P, Glasgow R, Masharani UA. A longitudinal study of affective and anxiety disorders, depressive affect and diabetes distress in adults with type 2 diabetes. Diabet Med. 2008;25(9):1096-1101. doi:10.1111/j.1464-5491.2008.02533.x

27. Nanayakkara N, Pease A, Ranasinha S, et al. Depression and diabetes distress in adults with type 2 diabetes: results from the Australian National Diabetes Audit (ANDA) 2016. Sci Rep. 2018;8(1):1-10. doi:10.1038/s41598-018-26138-5

28. Sankar P, Sasikumar P, Medayil R, Jacob R, Sasidharan S. High prevalence of distress among patients with Type 2 Diabetes (T2DM) - a Hospital-Based Cross-Sectional Study from South India. Am Diabetes Assoc. 2018;67(1).

29. Tol A, Baghbanian A, Sharifirad G, et al. Assessment of diabetic distress and disease related factors in patients with type 2 diabetes in Isfahan: a way to tailor an effective intervention planning in Isfahan-Iran. J Diabetes Metab Disord. 2012;11(1):20. doi:10.1186/ 2251-6581-11-20 


\section{Publish your work in this journal}

Diabetes, Metabolic Syndrome and Obesity: Targets and Therapy is an international, peer-reviewed open-access journal committed to the rapid publication of the latest laboratory and clinical findings in the fields of diabetes, metabolic syndrome and obesity research. Original research, review, case reports, hypothesis formation, expert opinion and commentaries are all considered for publication. The manuscript management system is completely online and includes a very quick and fair peer-review system, which is all easy to use. Visit http://www.dovepress.com/testimonials.php to read real quotes from published authors.

Submit your manuscript here: https://www.dovepress.com/diabetes-metabolic-syndrome-and-obesity-targets-and-therapy-journal 